\title{
Oxytocin blocks pet dog (Canis familiaris) object choice task performance being predicted by owner-perceived intelligence and owner attachment.
}

\author{
Jessica Lee Oliva ${ }^{1}$, Jean-Loup Rault², Belinda Appleton ${ }^{3}$, Alan Lill ${ }^{4}$
}

A positive association has been found between owner-rated dog cognition and owner-perceived closeness to their dog, using the Perceptions of Dog Intelligence and Cognitive Skills (PoDIaCS) survey and the Monash Dog Owner Relationship Scale (MDORS). Oxytocin has been positively associated with bonding in mammals and with non-verbal intelligence in humans and could therefore explain this relationship between owner-rated questionnaires. The aims of this study were to ascertain: i) whether a pet dog's performance on an object choice task (OCT), which objectively measures dogs' ability to use human non-verbal, social gestures to find a food reward, could be predicted by their owners' scores on three different surveys: (a) the MDORS, (b) the Pet Attachment Questionnaire (PAQ), which measures levels of anxious and avoidant attachment styles, and (c) a modified version of the PoDIaCS, and ii) if intranasal administration of oxytocin to dogs, known to enhance dogs' performance on such tasks, would disable the ability of an owner to predict their dogs' performance. It was hypothesized that higher ratings of owner-reported closeness to their dog, and higher ratings of owner-perceived intelligence of their dog, would positively predict dog OCT performance after saline, but not after oxytocin. Seventy-five pet dogs and their owners were recruited to participate in two OCTs, 5-15 days apart, once after the dog received intranasal oxytocin and once after receiving saline. Owners completed the PoDIaCS and another survey relating to pet ownership before OCT 1 , and the MDORS and PAQ before OCT 2. After saline administration, scores on the anxious subscale of the PAQ were a negative predictor of dog OCT performance using pointing cues, while subscale 6 of the PoDIaCS, 'contagion of human emotions', positively predicted performance using gazing cues. None of the questionnaire subscales were predictive of performance on the OCT after oxytocin administration. Results suggest that a dog s 'natural' ability to follow human pointing cues and anxious attachment in owners are inversely related, whilst a dog's 'natural' ability to follow human gazing cues is positively related to ownerrated empathic ability of the dog.

Pet Behaviour Science | 2016, Vol. 1, 31 -46

Jessica Lee Oliva ${ }^{1}$, Jean-Loup Rault ${ }^{2}$, Belinda Appleton $^{3}$, Alan Lill ${ }^{4}$

1. School of Biological Sciences,

Monash University

2. Animal Welfare Science Centre,

University of Melbourne

3. Life and Environmental Sciences,

Deakin University, Geelong

4. School of Life Sciences, La Trobe

University, Melbourne

Australia.

Keywords:

attachment, bonding, dog,

owner, oxytocin

\section{HIGHLIGHTS}

This study demonstrates that an owner's style of attachment to his/her dog may affect both the type of human social cue that the dog can use, and the degree to which it can do so.

The study also reveals the importance of past experiences of bonding, with both pets and children, in both the owners' perceptions of their dog's cognitive skills, and the style of attachment to it. 
This has implications for training dogs, both for working roles and for pet obedience, which may be complicated by the attachment style of the handler/owner.

The study also showed that administration of intranasal oxytocin, which increases dogs' performance on OCTs, diminished the relationship between owner attachment and dogs' OCT performance.

\section{INTRODUCTION}

Like human infants, the domestic dog displays attachment behaviours to humans that are absent in even intensively hand-reared wolves (Topál et al. 2005), the phylogenetically closest species to the domestic dog (Pang et al. 2009). It appears as though the domestication of dogs and subsequent exploitation of them as human companion animals has facilitated the formation of human-dog bonding. One way to evaluate the strength of a human-dog bond is by using questionnaires targeting the dogs' owners. In 2006, a 28-item questionnaire, the Monash Dog Owner Relationship Scale (MDORS), was developed; it quantifies the 'perceived emotional closeness' of the human-dog bond, the degree of 'dog-owner interactions', as well as the 'perceived costs' (both monetary and to lifestyle) involved in the ownership (Dwyer et al. 2006).

The strength of the bond, however, does not provide an indication of attachment style. Ainsworth et al. (1978) first demonstrated that human infants demonstrate different styles of attachment to their mothers and classified them as either 'secure' or 'insecure'. Insecure attachment can be characterised by anxious (anger or rejection of proximity seeking with their mothers after a period of separation) or avoidant (inconsistencies in greeting their mother after a period of separation) behaviours in a strange situation (Ainsworth et al.). It has been postulated that internal working models of attachment are developed in infancy and are carried forward into adulthood (for a review see, Bretherton and Munholland 2008). In adulthood, a secure style of attachment is characterised by a relative ease and comfort in close relationships, with minimal distressing fears of abandonment. An anxious style of attachment is characterised by a desire to be very close in relationships, often to the point which is uncomfortable for the partner, and accompanied by fears of abandonment and inadequacy (Brennan et al. 1998). On the other hand, an avoidant style of attachment is characterised by an uncomfortableness in being too close to, or dependent on, others (Brennan et al. 1998). Recently, Zilcha-Mano et al. (2011) developed a 26-item questionnaire to evaluate these human, adult internal working models of attachment in relation to pets, the Pet Attachment Questionnaire (PAQ). In line with literature regarding the different styles of attachment towards other adults (Brennan et al.), anxious attachment to a pet involves constant thoughts that something bad might happen to their pet and that they will be left alone, resulting in a constant desire to be near their pet and frustration when their pet does not reciprocate with the same need for closeness (ZilchaMano et al.). On the other hand, avoidant attachment involves feelings of discomfort when their pet gets too close to them and an avoidance of intimacy with their pet (Zilcha-Mano et al.). Absence of anxious and avoidant attachment types would suggest a secure attachment in which the owner is comfortable with the level of intimacy their pet shows them and is not affected by distressing thoughts or feelings (ZilchaMano et al.). Interestingly, while the PAQ anxious subscale is moderately correlated with both the anxious and avoidant subscales of the Experiences in Close Relationships Scale (ECR), which measures anxious and avoidant attachment in human relationships (Brennan et al.), the PAQ avoidant subscale is only weakly correlated with the ECR anxious subscale. This suggests that people with anxious internal working models of attachment are likely to form an insecure style of attachment to their pet, which is likely to be anxious in nature, but could also be avoidant. On the other hand, people with avoidant internal working models of attachment are also likely to form an insecure attachment to their pets, but which is anxious in nature. This suggests that a pet may allow someone with an avoidant internal working model of attachment to interact with them in a way that they are unable to do with other humans.

Whilst questionnaires are good tools for quantifying the human-dog bond, they obviously cannot be used on dogs and so, are inherently biased towards the owner's perspective. Currently, there is no biological 
marker to assess mammalian bonding; however, many studies have implicated oxytocin as having potential in this role, including in human-dog bonds. In a pioneering study, Odendaal and Meintjes (2003) found that when humans interacted positively with a dog, gently touching and talking to it, mean arterial blood pressure decreased in both species at the same time serum levels of oxytocin increased significantly, and this was significantly greater than if the human was simply relaxing whilst quietly reading a book. This study employed both men and women, and male and female dogs of differing breeds, but these groupings were not accounted for in the analysis. To account for these potentially confounding variables, Miller et al. (2009) replicated Odendaal and Meintjes' study using 10 men and 10 women and analysed data for the sexes separately. Interestingly, women's oxytocin secretion significantly increased, whilst men's secretion level significantly decreased after interaction with their dogs. The reason for this gender dichotomy is unknown; however, it may be due to the influence of sex hormones, known to modulate both the oxytocin peptide and the oxytocin receptor (for a review see, Gabor et al. 2012), or differences in the type of interaction between male and female humans, and dogs. For example, although not recorded in Miller et al.'s study, calm, soft petting may be more common from women, whilst rough play may be more common from men. Indeed, it was demonstrated that plasma cortisol concentrations rose in dogs petted for twenty minutes by men after a venipuncture procedure, but not in dogs petted by women (Hennessy et al. 1997), indicating that, contrary to women, men did not stimulate a significant anxiolytic effect in dogs petted after venipuncture. However, when men were trained to pet in a similar fashion to most women, no differences between cortisol levels in dogs petted by men and women were evident (Hennessy et al. 1998). There was, however, considerable individual variability in serum oxytocin levels among the men and among the women in Miller et al.'s study. In addition, one woman and one man appeared as outliers, with values two standard deviations greater than the mean. The authors noted that the aberrant woman had the greatest number of pet dogs of all participants in the study, whilst the man was the only participant with small children. This might suggest that their oxytocinergic systems had been primed by past bonding experiences.
However, caution should be applied when interpreting these findings because while Odendaal and Meintjes used established chromatographic methods to measure oxytocin, Miller et al. employed enzyme immunoassay methods without prior serum extraction, which has recently been shown to be necessary in obtaining valid results in plasma (Christensen et al. 2014; Szeto et al. 2011). Miller et al. also obtained values much higher than the normal biological range yielded using validated methods (Christensen et al.; McCullough et al. 2013).

It is also important to note that both of the abovementioned studies measured peripheral oxytocin concentrations, which may not reflect central oxytocin function as the peptide does not readily pass the bloodbrain barrier (Robinson 1983; Veening et al. 2010) and can be independently released in the brain and in the body (Amico et al. 1990; Engelmann et al. 2000; Ludwig and Leng 2006; Robinson and Jones 1982). Despite this, peripheral measures of oxytocin concentrations have continued to be the most widely investigated neurochemical metric in human-dog bonding studies (Nagasawa et al. 2009; Nagasawa et al. 2015; Handlin et al. 2011; Mitsui et al. 2011). Keeping gender and dog breed constant by only including female humans and male Labrador dogs, Handlin et al. found that plasma oxytocin levels significantly increased in both the dog and female owner after just three minutes of petting, stroking and talking to the dog. However, this study's findings also need to be interpreted with caution as they too carried out enzyme immunoassays using unextracted plasma samples, and obtained unnaturally high levels of oxytocin. In addition, when analysing grouped data, it is difficult to conclude which dogs, if any, are more bonded with their owners. To investigate this, Nagasawa et al. separated participants into two distinct groups, one which expressed a significantly higher perceived degree of satisfaction and communication with their dogs than the other group. After 30 minutes of interaction with their dogs, members of the former group excreted significantly higher concentrations of oxytocin in their urine than members of the latter group, and owned dogs that gazed at them for longer periods within the 30 minute interaction. This was only true, however, for interactions where owners were instructed to look back at their dogs, and not for interactions where they were 
instructed not to look back at their dogs. Urine is not yet a validated method for measuring oxytocin (McCullough et al. 2013), however, this may support the role of oxytocin as at least one of the neuropeptides involved in human-dog bonding, and also of gaze as an important factor, similar to the situation observed in human infants (Striano et al. 2006; Dickstein et al. 1984). The importance of gaze was further reinforced in a similar study which demonstrated that mutual dogowner gaze increased oxytocin in the owner's urine, and intranasally administering oxytocin increased gazing behaviour in female dogs, which subsequently increased their owners' urinary oxytocin levels (Nagasawa et al. 2015).

Intranasal administration of neuropeptides is a popular method to study their central effects because, despite a poor understanding of their mechanisms of action (Leng and Lugwig 2016), increased levels of neuropeptides can be found in brain dialysates (Neumann et al. 2013) and cerebrospinal fluid (CSF) (Born et al. 2002; Dal Monte et al. 2014; Rault 2016; Striepens et al. 2013) following administration. In humans, intranasally administered oxytocin increases the salience of social cues (see review by Bartz et al. 2011), as well as causing an increase in gaze towards the eye region of other human faces (Guastella et al. 2008) (also observed in monkeys (Dal Monte et al. 2014)). Furthermore, variations in the oxytocin receptor gene have been associated with human infant attachment (Chen et al. 2011) and interact with internal working models of attachment in adulthood in assessing risk and in feelings of closeness (Denes 2015). Variations in this gene have also been associated with non-verbal intelligence (Lucht et al. 2009), amygdala activation during the processing of emotionally-salient human faces (Tost et al. 2010), performance on the "reading the mind in the eyes" test (Rodrigues et al. 2009) and autism (Wu et al. 2005), a syndrome characterized by social deficits (for a review see, Volkmar 2011). In dogs variations in the oxytocin receptor gene have been associated with proximity seeking towards humans and friendliness towards strangers (Kis et al. 2014). Intranasal oxytocin in dogs has been shown to increase positive expectations (Kis et al. 2015), decrease friendliness in response to a threatening person (Hernádi et al. 2015), and increase mutual gaze with their owners (Nagasawa et al. 2015).
It has also been shown to influence dogs' ability to perform an Object Choice Task (OCT) which tests their ability to use human social cues to find hidden food treats (Oliva et al. 2015). Data from this study will be drawn on in the current investigation of the relationship between the dog owners' perceptions of the strength of the bond with their dog and of the dog's intelligence, and the dog's actual performance level on the OCT (see Table 1 for relevant means and standard deviations).

Recently a survey was developed that aimed to determine owner-perceived cognitive abilities in dogs (in general), the Perceptions of Dog Intelligence and Cognitive Skills (PoDIaCs) survey (Howell et al. 2013). The survey measures owner-perceived abilities across eight cognitive domains: 'recognition of human emotions', 'learned problem-solving abilities', 'instinctive awareness of human attention', 'learned awareness of human attention', 'deception', 'contagion of human emotions', 'instinctive problem-solving abilities' and 'general intelligence compared to humans'. While each cognitive domain was significantly correlated with the second subscale of the MDORS, the owner's 'perceived emotional closeness' with his/her dog (Howell et al.), it is currently unknown if either of these variables relates to actual cognitive ability.

If central oxytocin facilitates i) bonding of a dog to a human and ii) the ability of the dog to use human social cues, we would expect to find a positive correlation between owner-rated measures of bonding and social cognition, and actual ability of the dogs to perform well on a task that tests their ability to use human social cues. Hence, the first aim of our study was to elucidate whether dog owners' scores on the MDORS, PAQ and PoDIaCS were related to the dogs' actual performance on an OCT. In particular, we expected to find positive associations between the MDORS subscale 2, which measures the 'perceived emotional closeness' of the bond, and the PoDIaCS subscales 3 or 4 , which contain questions appropriate to the OCT, such as "my dog can instinctively understand human gestures like pointing at food or toys" (subscale 3) and "my dog can learn to understand human gestures like pointing at food or toys" (subscale 4), and OCT scores. The influence of attachment style 
(known to be affected by the oxytocin receptor gene (Chen et al. 2011; Denes 2015)) and other factors relating to the dog and owner that may influence oxytocin function (such as parental and pet ownership history (Miller et al. 2009) and order of intranasal treatments (Oliva et al. 2015)) were also explored. The second aim of the study was to investigate the effect of intransally administering dogs with oxytocin on this predictive relationship. Due to the fact the oxytocin enhances dog performance on OCTs, we expected this predictive relationship to be diminished as dogs with owners scoring low on the MDORS subscale 2 and the PoDIaCS subscales 3 and 4 may be performing the task equally as well as dogs with owners who score highly on these subscales, after oxytocin administration.

\section{METHODS}

Study animals

Seventy-five pet dogs ( 33 males, 42 females) and their owners (14 males, 48 females) were recruited for the study. Owners were recruited voluntarily through poster advertisements at Monash University's Caulfield and Clayton campuses, as well as through University enewsletters and social media websites. The dataset of behavioural performance is the same as published in Oliva (2015). The study was approved by the Monash University School of Biological Sciences Animal Ethics Committee (BSCI/2013/07) and the Monash University Human Research Ethics Committee (CF12/08472012000385).

\section{Materials}

$0.5 \mathrm{ml}$ saline solutions containing oxytocin (24 IU) or saline only, were administered to the nostrils of the dogs using a mucosal atomizer device connected to a $1 \mathrm{~mL}$ syringe. Four identical, opaque spaniel bowls were used to conceal the food treats and OCT scores (out of 20 per cue) were recorded by the experimenter using pen and paper. A modified version of the PoDIaCS (specifically about the owner's dog, as opposed to dogs in general), and another questionnaire about other factors relating to the dog and owner that may influence oxytocin function were administered to participants before the first OCT (refer to the Appendix). Each cognitive domain of the PoDIaCS has been previously found to have good internal consistency, with Cronbach alpha values (a co-efficient of internal consistency commonly used as an estimate of reliability) of 0.74-0.91 (Howell et al. 2013). The MDORS and PAQ were administered before the second $\mathrm{OCT}$, and completed by participants using pen and paper. The MDORS scale has been found to have good content validity and good internal consistency, with Cronbach alpha values of 0.84 for both 'perceived emotional closeness' (subscale 2) and 'perceived costs' (subscale 3) (Dwyer et al. 2006). The 'dog-owner interaction' (subscale 1) co-efficient was not as strong, with an alpha value of 0.67 (Dwyer et al.). The PAQs questionnaire has also been found to have good content and construct validity, good test-retest reliability $(\mathrm{r}=.75)$ and good internal consistency, with Cronbach alpha values for avoidant attachment between 0.84 and 0.91 and for anxious attachment between 0.86 and 0.92 , with a weak, non-significant correlation between the two $(r=$ 0.1 to 0.4 ) (Zilcha-Mano et al. 2011).

\section{Procedure}

Dogs were pseudo-randomly separated into two groups: those that received oxytocin in their first session and saline in their second session (oxy-sal) and vice versa (sal-oxy). Upon arrival at the testing room in session 1, the dogs received one of two intranasal treatments, oxytocin or saline. When dogs arrived for their second session, they received the other intranasal treatment. There was a 5-15 days washout period between sessions. Both the experimenter and the dog owner were 'blind' to which treatment the dog received on which day, as solutions were labelled ' $\mathrm{A}$ ' or ' $\mathrm{B}$ ' and only decoded after the study concluded. Regardless of which group the dogs were allocated to for the experimental study, owners of all dogs completed the questionnaires in the same order mentioned above, while the dog was free to roam the testing room, interact with the owner and experimenter, or wander outside. The questionnaires were completed in this order so as not to influence the owner's opinion about their dogs' ability to perform the task before completion of the PoDIaCS. Forty-five minutes after the treatment was administered, the OCT commenced, which involved (a) pre-training (before each 10 trial block of the OCT proper): four correct trials in a row where the dog was shown a food treat being dropped 
into one of two dog bowls, either side of the experimenter (delivered using the ipsilateral hand from a kneeling position, $75 \mathrm{~cm}$ from the target) (b) 20 trials (block 1 and block 3) where the dog was given a momentary distal pointing cue (a 1-2 second point delivered using the ipsilateral index finger from the same kneeling position) to indicate the location of the hidden food reward located in one of the two dog bowls and (c) 20 trials (block 2 and block 4) using a gaze cue (a 1-2 second gaze shift delivered from the same kneeling position, keeping the head straight). Five control trials per block, where no cue was given, were also delivered to ensure the dogs were not relying on scent to solve the task. The task usually lasted between 45 and 60 minutes and was carried out by the experimenter with the help of the owner, who called the dog back to the starting position between trials and restrained it until the experimenter said the release word "OK". The experimenter recorded the score for each trial as either correct (if the dog approached the bowl with the hidden food treat) or incorrect (if the dog approached the empty bowl or the experimenter) before starting the next trial. Trials were also considered incorrect if the dog made no choice but was deemed motivated to complete the task by participating when two of the easier pre-training cues were then given as a test of motivation. Data pertaining to OCT performance is the same as that which was published in Oliva (2015) and means and standard deviations pertaining to this data are reported in Table 1.

Table 1. Mean ( \pm standard deviation) correct object choices out of 20 for all dogs combined, according to treatment.

\begin{tabular}{|lcccccc|}
\hline \multicolumn{4}{|c}{ Oxytocin } & \multicolumn{4}{c|}{ Saline } \\
& $M$ & $S D$ & $N$ & $M$ & $S D$ & $N$ \\
\hline $\begin{array}{c}\text { Point } \\
\text { total }\end{array}$ & 15.73 & 3.01 & 63 & 15.45 & 3.63 & 64 \\
$\begin{array}{l}\text { Gaze } \\
\text { total }\end{array}$ & 9.52 & 2.17 & 62 & 9.51 & 2.09 & 63 \\
\hline
\end{tabular}

\section{Data analysis}

The raw scores (out of 20) were calculated for each cue used in the OCT proper after oxytocin and saline administration and entered into IBM SPSS Statistics version 22 (SPSS IBM, New York, U.S.A., 2013). Totals for each subscale of the PoDIaCS, MDORS and PAQ were calculated and divided by the number of items in that subscale to obtain overall mean score values. Some items were reverse-scored according to the scoring instructions for the particular questionnaire. All MDORS subscales were scored such that higher values reflect greater relationship quality, so higher values on MDORS subscale 3 'perceived costs' actually represent lower perceived costs.

Cronbach alpha values were calculated to obtain an indication of internal consistency for each of the subscales used in the current sample.

Pearson's correlations were run between the cognition and the attachment subscales to see if previous findings of an association between owner-reported bonding/attachment and owner-perceived cognition ratings (Howell et al. 2013) were replicated in our study, and to investigate the effect of attachment style.

Multiple regression was employed to test the predictive power of other factors relating to the dog, and ownership of the dog, in response to each subscale. To test whether dogs' performance on the OCT could be predicted by i) their owners' questionnaire data, ii) other factors relating to ownership, and iii) gender of the $\operatorname{dog}$ and order of treatment administration, hierarchical multiple regression was run for each of the outcome variables: point oxytocin, point saline, gaze oxytocin and gaze saline. Dummy variables were created for the 'other factors' predictors: previous dog owner, previous non-dog owner (owners with a history of owning pets other than dogs), owner parental history, young dog, old dog, gender of owner, entire dog, inside dog. Dummy variables were also created for order of treatment administration and gender of dog. Each subscale of the PoDIaCS, MDORS and PAQ was entered at step 1 of the regression; 'other factors' were entered at step 2 and gender and order of treatment administration were entered at step 3 . Preliminary analyses were conducted for each of the regressions to ensure that there was no violation of the assumptions of normality, linearity, multicollinearity and homoscedasticity. An alpha level of 0.05 was selected for all tests of significance. 


\section{RESULTS}

Chronbach alpha values for each subscale are given in Table 2.

Sample means and standard deviations for each of the subscales are given in Table 3. the MDORS subscales 1-3 nor the PAQ anxious subscale. However, 'previous dog owner' negatively influenced PoDIaCS 6 scores (contagion of human emotions), whilst parental history positively influenced PODIACS 6 scores, with $20 \%$ of the variance being explained by the model: F8, $66=2.11 ; \mathrm{P}=.047$. Male

\begin{tabular}{|lccl|}
\hline \multicolumn{1}{|c}{ Subscale } & Cronbach Alpha & \multicolumn{2}{c|}{ Previous Cronbach Alpha(s) } \\
\hline MDORS 1 & 0.72 & 0.84 & Dwyer et al. 2006 \\
MDORS 2 & 0.77 & 0.84 & Dwyer et al. 2006 \\
MDORS 3 & 0.74 & 0.67 & Dwyer et al. 2006 \\
PAQ avoidant & 0.83 & $0.84-0.91$ & Zicha-Mano et al. 2011 \\
PAQ anxious & 0.86 & $0.86-0.92$ & Zicha-Mano et al. 2011 \\
PoDlaCS 1 & 0.81 & 0.91 & Howell et al. 2013 \\
PoDlaCS 2 & 0.89 & 0.91 & Howell et al. 2013 \\
PoDlaCS 3 & 0.64 & 0.80 & Howell et al. 2013 \\
PoDlaCS 4 & 0.73 & 0.75 & Howell et al. 2013 \\
PoDlaCS 5 & 0.88 & 0.89 & Howell et al. 2013 \\
PoDlaCS 6 & 0.66 & 0.75 & Howell et al. 2013 \\
PoDlaCS 7 & 0.84 & 0.74 & Howell et al. 2013 \\
PoDlaCs 8 & 0.91 & 0.74 & Howell et al. 2013 \\
\hline
\end{tabular}

Table 2. Cronbach alpha values for each subscale of the PoDIaCS, MDORS and PAQ, compared with values previously found in the literature. $\mathrm{N}=75$

Pearson's correlations between each of the perceived intelligence subscales and each of the attachment subscales are given in Table 4.

As evident from Table 4, only subscale 8 of the PoDIaCS was positively associated with the MDORS subscale 2, subscales $3,5,8$ were positively associated with the MDORS subscale 1 and the PoDIaCS subscale 8 was positively associated with the MDORS subscale 3. Furthermore, we found a positive association between subscale 6 of the PoDIaCS and PAQ anxious subscale.

To test whether any 'other factors' relating to the dog and ownership of the dog contributed to questionnaire scores, multiple regressions were run for each subscale of each questionnaire with 'other factors' as predictor variables. None of the factors were successful in predicting scores for the PoDIaCS subscales 1-5, and 8, owners and previous non-dog owners positively influenced PoDIaCS 7 scores (instinctive problemsolving abilities), with $23 \%$ of the variance being explained by the model: F8, $66=2.49 ; \mathrm{P}=.020$. Parental history positively influenced PAQ avoidant scores, with $23 \%$ of the variance being explained by the model: $\mathrm{F} 8$, $66=2.52 ; \mathrm{P}=.019$. 


\begin{tabular}{|lcc|}
\hline \multicolumn{1}{|c}{ Subscale } & M & SD \\
\hline PoDlaCS 1: recogition of human emotions & 3.86 & 0.55 \\
PoDlaCS 2: learned problem-solving abilities & 3.82 & 0.62 \\
$\begin{array}{l}\text { PoDlaCS 3: instinctive awareness of human } \\
\text { attention }\end{array}$ & 3.75 & 0.68 \\
$\begin{array}{l}\text { PoDlaCS 4: learned awareness of human } \\
\text { attention }\end{array}$ & 4.34 & 0.50 \\
PoDlaCS 5: deception & 3.11 & 1.03 \\
PoDlaCS 6: contagion of human emotions & 3.06 & 0.66 \\
PoDlaCS 7: instinctive problem-solving abilities & 2.80 & 0.80 \\
PoDlaCS 8: general intelligence compared with & 2.36 & 0.97 \\
humans & 3.83 & 0.60 \\
MDORS 1: dog-owner interactions & 3.91 & 0.52 \\
MDORS 2: perceived emotional closeness & 4.00 & 0.53 \\
MDORS 3: perceived costs & 1.51 & 0.51 \\
PAQ avoidant & 2.33 & 0.86 \\
\hline PAQ anxious & & \\
\hline
\end{tabular}

Table 3. Descriptive statistics for owners' scores on each subscale of the PoDIaCS, MDORS and PAQ. $\mathrm{N}=75$

Regression co-efficients for the above-mentioned significant models can be found in Table 5 .

Of the 75 dogs involved in the study, two males and 11 females did not complete the two sessions of the experimental study successfully, leaving a total of 31 males and 31 females in the following hierarchical multiple regression analysis.

None of the models were able to predict scores for pointing or gazing after oxytocin administration. For pointing scores, the subscale scores entered at Step 1 explained an insignificant $18 \%$ of the variance: F13, $49=$ $0.84 ; \mathrm{P}=.62$. The 'other factors' were entered at Step 2 but did not contribute significantly to the model: R2 change $=.18 ; \mathrm{F}$ change $21,41=1.39 ; \mathrm{P}=.23$. Additionally, 'oxytocin administered first' and 'female' were entered at Step 3, but they too did not significantly contribute to the model: R2 change $=.01 ; \mathrm{F}$ change 23, $39=0.23$; $\mathrm{P}=.79$.
For gazing scores, the subscale scores entered at Step 1 explained an almost significant $35 \%$ of the variance: F13, $48=1.93 ; \mathrm{P}=.050$ (with only the PoDIaCS subscale 4 - learned awareness of human attention - negatively predicting performance). Once again, the 'other factors' entered at Step 2 did not contribute significantly to the model: R2 change $=.09 ; \mathrm{F}$ change $21,40=0.74 ; \mathrm{P}=.66$, and 'oxytocin administered first' and 'female' also didn't significantly contribute to the model when entered at Step 3: R2 change $=.02$; F change 23, $38=0.76$; $\mathrm{P}=.48$.

In contrast, model 3 was successful in predicting pointing scores after saline administration and model 1 was successful in predicting gazing scores after saline administration. For pointing scores, the subscale scores entered at Step 1 explained an insignificant $29 \%$ of the variance: $\mathrm{F} 13,50=1.57 ; \mathrm{P}=.13$. The 'other factors' entered at Step 2 did not contribute significantly to the model: R2 change $=.07 ; \mathrm{F}$ change $21,42=0.58 ; \mathrm{P}=.79$. 
However, when 'oxytocin administered first' and 'female' were entered at Step 3, they did contribute significantly to the model: R2 change $=.22 ; \mathrm{F}$ change 23 , $40=10.44 ; \mathrm{P}<.0001$.
OCT with pointing cues after saline administration; indeed, dogs owned by people who score one point higher on this subscale than other dog owners would be expected to score 1.49 points lower on the task than dogs owned by people who score one point lower on this subscale. Scores were also likely to be lower for

\begin{tabular}{|lccccc|}
\hline \multicolumn{1}{|c}{ PoDlaCs subscales } & $\begin{array}{c}\text { MDORS 1: } \\
\text { dog-owner } \\
\text { interactions }\end{array}$ & $\begin{array}{c}\text { MDORS 2: } \\
\text { perceived } \\
\text { emotional } \\
\text { closeness }\end{array}$ & $\begin{array}{c}\text { MDORS 3: } \\
\text { perceived } \\
\text { costs }\end{array}$ & $\begin{array}{c}\text { PAQ: } \\
\text { avoidant }\end{array}$ & $\begin{array}{c}\text { PAQ: } \\
\text { anxious }\end{array}$ \\
\hline $\begin{array}{l}\text { 1: recognition of human } \\
\text { emotions }\end{array}$ & 0.22 & 0.15 & 0.02 & 0.07 & 0.04 \\
$\begin{array}{l}\text { 2: learned problem solving } \\
\text { abilities }\end{array}$ & 0.16 & -0.11 & -0.07 & 0.18 & -0.04 \\
$\begin{array}{l}\text { 3: instinctive awareness of } \\
\text { human attention }\end{array}$ & $0.29^{* *}$ & 0.17 & 0.19 & -0.08 & 0.13 \\
$\begin{array}{l}\text { 4: learned awareness of } \\
\text { human attention }\end{array}$ & 0.20 & 0.03 & -0.03 & -0.07 & 0.01 \\
$\begin{array}{l}\text { 5: deception } \\
\begin{array}{l}\text { 6: contagion of human } \\
\text { emotions }\end{array}\end{array}$ & $0.25^{*}$ & -0.16 & -0.08 & 0.01 & -0.18 \\
$\begin{array}{l}\text { 7: instinctive problem- } \\
\text { solving abilities }\end{array}$ & 0.07 & 0.14 & -0.03 & 0.20 & $0.27^{*}$ \\
8: general intelligence \\
compared with humans
\end{tabular}

Table 4. Pearson Correlation Matrix Describing Relationships between the 8 PoDIaCS subscales and the 3 MDORS and 2 PAQ subscales. $\mathrm{N}=75$

For gazing scores, the subscale scores entered at Step 1 explained a significant $35 \%$ of the variance: $\mathrm{F} 13,49=$ 2.07; $\mathrm{P}=.034$. The 'other factors' entered at Step 2 did not significantly contribute more to the model: $\mathrm{R} 2$ change $=$ .14; $\mathrm{F}$ change $21,41=1.41 ; \mathrm{P}=.22$, nor did 'oxytocin administered first' and 'female' when entered at Step 3: $\mathrm{R} 2$ change $=.02 ; \mathrm{F}$ change $23,39=0.77 ; \mathrm{P}=.47$.

Regression coefficients for the above-mentioned significant models are given in Table 6.

As evident from Table 6, the PAQ anxious subscale was a significant negative predictor of performance on the female dogs and higher for dogs that received oxytocin on their first visit (thus making pointing after saline scores their pointing scores for their second visit). In contrast, the PoDIaCS 6 subscale (contagion of human emotions) was a significant positive predictor of performance on the OCT with gazing cues after saline administration whereby dogs owned by people who score one point higher on this subscale than other dog owners would be expected to score 1.72 points higher on the task than dogs owned by people who score one point lower on this subscale. 
Table 5. Unstandardized $(B)$ and Standardized $(\beta)$ Regression Coefficients for each Predictor Variable in a Hierarchical Multiple Regression for PoDIaCS 6, PoDIaCS 7 and PAQ avoidant Scores.

\begin{tabular}{|c|c|c|c|}
\hline & B & SE B & $\beta$ \\
\hline \multicolumn{4}{|l|}{ PoDlaCs 6} \\
\hline Constant & 2.92 & 0.25 & \\
\hline Young dog & 0.17 & 0.17 & 0.13 \\
\hline Old dog & -0.09 & 0.22 & -0.05 \\
\hline Entire & 0.33 & 0.30 & 0.13 \\
\hline Male owner & 0.35 & 0.20 & 0.21 \\
\hline Previous dog owner & $-0.49^{*}$ & 0.21 & -0.30 \\
\hline Previous non-dog owner & 0.21 & 0.18 & 0.15 \\
\hline Parental history & $0.38^{*}$ & 0.16 & 0.29 \\
\hline Inside dog & 0.09 & 0.19 & 0.06 \\
\hline \multicolumn{4}{|l|}{ Note $\mathrm{R}^{2}=.20,{ }^{*} \mathrm{P}<.05$} \\
\hline \multicolumn{4}{|l|}{ PoDlaCs7 } \\
\hline Constant & 2.62 & 0.31 & \\
\hline Young dog & -0.03 & 0.20 & -0.02 \\
\hline Old dog & -0.14 & 0.27 & -0.06 \\
\hline Entire & -0.60 & 0.36 & -0.19 \\
\hline Male owner & $0.66^{\star *}$ & 0.25 & 0.32 \\
\hline Previous dog owner & -0.30 & 0.25 & -0.15 \\
\hline Previous non-dog owner & $0.82^{* \star \star}$ & 0.22 & 0.48 \\
\hline Parental history & -0.11 & 0.20 & -0.07 \\
\hline Inside dog & -0.18 & 0.23 & -0.09 \\
\hline \multicolumn{4}{|l|}{ Note $R^{2}=.23, * * P<.01, \ldots+\cdots P<.001$} \\
\hline \multicolumn{4}{|l|}{ PAQ avoidant } \\
\hline Constant & 1.52 & 0.19 & \\
\hline Young dog & 0.14 & 0.13 & 0.14 \\
\hline Old dog & -0.15 & 0.17 & -0.11 \\
\hline Entire & 0.18 & 0.23 & 0.09 \\
\hline Male owner & 0.30 & 0.16 & 0.23 \\
\hline Previous dog owner & -0.24 & 0.16 & -0.19 \\
\hline Previous non-dog owner & 0.16 & 0.14 & 0.15 \\
\hline Parental history & $0.31^{*}$ & 0.13 & 0.30 \\
\hline Inside dog & -0.21 & 0.14 & -0.17 \\
\hline
\end{tabular}




\begin{tabular}{|c|c|c|c|}
\hline & B & SE B & $\beta$ \\
\hline \multicolumn{4}{|l|}{ Model 3 - Point cues } \\
\hline Constant & 0.21 & 9.00 & \\
\hline PoDlaCs 1 & 0.39 & 1.16 & 0.06 \\
\hline PoDlaCs 2 & -1.33 & 1.12 & -0.21 \\
\hline PoDlaCs 3 & -0.30 & 0.85 & -0.05 \\
\hline PoDlaCs 4 & 2.07 & 1.30 & 0.25 \\
\hline PoDlaCs 5 & 0.51 & 0.53 & 0.15 \\
\hline PoDlaCs 6 & 0.30 & 0.98 & 0.05 \\
\hline PoDlaCs 7 & -0.54 & 0.86 & -0.12 \\
\hline PoDlaCs 8 & 0.71 & 0.67 & 0.19 \\
\hline MDORS 1 & 1.80 & 1.06 & 0.28 \\
\hline MDORS 2 & 0.67 & 1.34 & 0.09 \\
\hline MDORS 3 & -0.47 & 1.20 & -0.07 \\
\hline PAQ avoidant & 1.14 & 1.40 & 0.15 \\
\hline PAQ anxious & $-1.49^{\star}$ & 0.69 & -0.34 \\
\hline Entire & -1.39 & 1.70 & -0.10 \\
\hline Male owner & 1.58 & 1.44 & 0.16 \\
\hline Previous dog owner & 0.15 & 1.25 & 0.02 \\
\hline Previous non-dog owner & 1.61 & 1.37 & 0.20 \\
\hline Parental history & -2.12 & 1.08 & -0.29 \\
\hline Inside dog & 1.56 & 1.08 & 0.19 \\
\hline Young dog & 0.89 & 1.10 & 0.12 \\
\hline Old dog & 1.11 & 1.50 & 0.11 \\
\hline Female & $-3.20^{\star \star}$ & 0.96 & -0.44 \\
\hline Oxytocin First Visit & $3.12^{\star \star}$ & 0.88 & 0.43 \\
\hline
\end{tabular}

\begin{tabular}{|c|c|c|c|}
\hline \multicolumn{4}{|c|}{ Model 1 - gaze cues } \\
\hline Constant & 3.60 & 4.30 & \\
\hline PoDlacs 1 & -1.27 & 0.64 & -0.33 \\
\hline PoDlacs 2 & 0.65 & 0.59 & 0.18 \\
\hline PoDlacs 3 & -0.78 & 0.48 & -0.25 \\
\hline PoDlacs 4 & 0.05 & 0.62 & 0.01 \\
\hline PoDlacs 5 & 0.28 & 0.31 & 0.14 \\
\hline PoDlacs 6 & $1.72^{\star *}$ & 0.54 & 0.54 \\
\hline PoDlacs 7 & 0.31 & 0.41 & 0.12 \\
\hline PoDlacs 8 & -0.02 & 0.36 & -0.01 \\
\hline MDORS 1 & 0.16 & 0.61 & 0.04 \\
\hline MDORS 2 & -0.67 & 0.74 & -0.16 \\
\hline MDORS 3 & 1.17 & 0.67 & 0.29 \\
\hline PAQ avoidant & 0.45 & 0.78 & 0.10 \\
\hline PAQ anxious & 0.36 & 0.36 & 0.14 \\
\hline
\end{tabular}

Table 6. Unstandardized (B) and Standardized ( $\beta$ ) Regression Coefficients for each Predictor Variable in model 3 (MDP cues) and model 1 (gaze cues) of a Hierarchical Multiple Regression for Point and Gaze Cue Scores after Saline Administration on The Object Choice Task.

\section{DISCUSSION}

Contrary to our hypothesis, no significant, positive correlation was obtained between the MDORS 2 (perceived emotion closeness) and the PoDIaCS 3 (instinctive awareness of human attention) or 4 (learned awareness of human attention). None of these subscales predicted OCT scores (after saline nor oxytocin) either, although, interestingly, PoDIaCS 4 was shown to negatively predict gaze scores after oxytocin, however this model did not quite reach significant overall. There was, however, a significant, positive correlation between the MDORS 2 and the PoDIaCS 8 (general intelligence compared to humans). In addition, the PAQ anxious subscale negatively predicted OCT scores (as well as being female and receiving oxytocin second) using pointing cues and the PoDIaCS 6 predicted OCT scores using gazing cues. In contrast to Howell et al.'s (2013) study, which showed a positive association between MDORS subscale 2 and all 8 subscales of the PoDIaCS, MDORS subscale 2 was correlated with only one of the eight cognitive domains assessed in the PoDIaCS, subscale 8 . The discrepancies between our findings and previous results are possibly due to the fact that whilst our modified version of the PoDIaCS assessed perceived intelligence and cognitive skills of owned dogs, Howell et al.'s original survey assessed perceived intelligence and cognitive skills of dogs in general. They may also be due to the differences in internal consistency, refer to Table 2, particularly the PoDIaCS subscale 3 which resulted in a questionable Cronbach alpha value of .64 in the current study but a much more acceptable value of .80 in Howell et al.'s study. For other subscales, such as 7 and 8, Cronbach alpha values in the current study are much higher than in Howell et al's study, however, Howell et al.'s study also had a much larger cohort of participants, so it is possible the discrepant findings are due to the current study having lower statistical power. The PoDIaCS subscale 8 was also associated with subscale 3 of the MDORS (perceived costs), which is consistent with Howell et al.'s findings, while the MDORS subscale 1 (dog-owner interactions), was associated with subscales 3: (instinctive awareness of human attention), 5: (deception) and 8, in the current study (and all but subscale 7 in the study by Howell et al.). Taken together, these findings suggest that time spent with one's dog is more important than how psychologically close one feels towards their dog in perception of intelligence and only minimally support our hypothesis that owners who are more closely bonded to their dog will perceive him/her to be more 
intelligent.

Additively, we found a positive association between subscale 6 of the PoDIaCS, (contagion of human emotions), and the PAQ anxious subscale. This may suggest that anxiously-attached owners believe more than non-anxiously attached owners that their dog can feel sad, afraid, angry and/or happy when its owner feels the same emotion. This may be a misperception, due to having higher levels of anxiety, or the result of these owners expressing more emotions, particularly negative ones, which their dog finds distressing and to which it reacts more overtly. However, our results suggest that dogs of owners who score highly on this subscale are more likely to perform more poorly on the OCT using pointing cues, in the absence of exogenous oxytocin administration. O'Farrell (1995, as cited in O'Farrell 1997) found a significant correlation between owner anxiety and over-excitement and displacement activities in the dog, hence, this poorer performance may be a direct effect of the anxiously attached owner who was present in the room at all times.

When 'other factors' relating to ownership were considered, it was found that PoDIaCS 6 scores (contagion of human emotions) were negatively influenced by the factor 'previous dog owner', whilst 'parental history' positively influenced these scores, suggesting that first time dog owners and owners who have had children are more prone to believe that their dogs feel their emotions more than experienced dog owners and owners who have not had children. 'Male owners' and 'previous non-dog owners' positively influenced PoDIaCS 7 scores (instinctive problemsolving abilities). This may highlight differences in interactions between male and female owners and their dogs (Hennessy et al. 1998, Hennessy et al. 1997) and also suggests that past experiences of pet ownership may affect the perception of current dog ownership, whereby experienced pet owners believe their dogs to have more instinctive problem-solving abilities. Furthermore, 'parental history' positively influenced PAQ avoidant scores, which suggests that owners who have had children are more likely to form avoidant type attachments to their dog, than owners who have not had children. According to Zilcha-Mano et al. (2011), there is no correlation between avoidant styles of attachment towards humans and towards pets.
Therefore, it is possible that due to the parent-offspring relationship(s) in their lives, the relationship to their pet is relatively low in priority and this is reflected as an avoidant owner-pet relationship.

Performance on the OCT after oxytocin administration could not be predicted by any of the statistical models. This is likely to be due to the fact that dogs' abilities to perform OCTs correctly are enhanced by oxytocin administration (Oliva et al. 2015) and therefore differs from what the owner would otherwise expect. While Oliva et al. were able to demonstrate an increase in dogs' ability to correctly use human social cues following oxytocin administration, it remains unknown why this is so. It may reflect an effect of oxytocin in increasing a dogs' ability to understand human gestures, or, in light of the findings relating to the PAQ anxious subscale and poorer performance on the OCT using pointing cues after saline, it could that mean that oxytocin, also known also for its anxiolytic properties (de Oliveira et al. 2012; Heinrichs et al. 2003), reduces the anxiety these dogs may 'absorb' from their owner, thereby disinhibiting their natural cognitive ability. Oxytocin's performance enhancing effects may also may explain why the PoDIaCS 4 was a negative predictor of performance, rather than a positive one as was hypothesized, in the almost significant multiple regression for gaze after oxytocin administration i.e. if the owners rated their dogs low for 'learned awareness of human attention' and the dogs performed better than expected due to oxytocin.

In contrast to the above-mentioned lack of predicative power following oxytocin administration, performance on the OCT after saline administration, could be predicted by the models. As previously mentioned, PAQ anxious scores negatively predicted OCT scores for pointing cues; thus, dogs owned by people who score higher on this subscale would be expected to perform more poorly on the task than dogs owned by people who score lower on this subscale. In addition, point scores after saline administration were likely to be lower for female dogs, suggesting that male dogs are more skilled at the OCT task, and higher for dogs performing the task for the second time (i.e. their second testing session). Findings in Oliva et al. (2015) suggest that this is a reflection of the enhanced performance from the oxy-sal group dogs being 
maintained in session 2.

Performance using gazing cues was predictable from scores on the PoDIaCS 6 subscale (contagion of human emotions) after saline administration i.e. dogs owned by people who score higher on this subscale would be expected to score higher on the task than dogs owned by people who score lower on this subscale. This is interesting because this subscale was also associated with the PAQ anxious subscale, which was negatively influenced by previously owning a dog and positively influenced by parental history. This suggests that past experiences of owning a dog or parenting a child may not only affect serum oxytocin levels (Miller et al. 2009), but perceptions about the current dog-owner relationship as well. This finding suggests that gaze is important in human-dog communication for dogs with owners who are anxiously attached to them and hence, potentially more likely to express their emotions to their dog, who may respond accordingly.

\section{CONCLUSIONS}

Overall, this study found little evidence supporting an association between owner-perceived closeness with their dog, owner perceptions of the intelligence of their dog and the actual intelligence of their dog as manifested in the OCT (performed after saline and oxytocin administration). The investigation did, however, reveal that past experiences of bonding, with both pets and children, affected owners' perceptions of the cognitive skills of the currently-owned dog and the style of attachment to it. Higher scores for anxious attachment to dogs significantly predicted lower scores on the OCT following saline administration using pointing cues. An association was also found between anxious attachment and perceived 'contagion of human emotions', which significantly predicted higher scores on the OCT following saline administration using gazing cues. This suggests that communicative signals delivered to dogs may differ between anxious and nonanxiously attached owners, affecting the human cues the dog learns to follow. Alternatively, communicative signals may be interpreted differently by dogs owned by anxiously-attached humans versus those owned by non-anxiously attached humans. As such, training dogs, both for working roles and for pet obedience, may be further complicated by the attachment style of the handler/owner.

\section{ACKNOWLEDGEMENTS}

We would like to thank the Clear Dog Shop and Love' em for sponsoring the study and providing dog food rewards. We would also like to thank Lachlan Macquarie, Department of Econometrics and Business Statistics, Monash University, for his statistical advice.

\section{REFERENCES}

Ainsworth M.D.S., Blehar M.C., Waters E., and Wall S. eds. 1978. Patterns of attachment: A psychological study of the strange situation. Hillsdale, NJ: Erlbaum.

Amico, J. A., Challinor, S. M., and Cameron, J. L. 1990. Pattern of Oxytocin Concentrations in the Plasma and Cerebrospinal Fluid of Lactating Rhesus Monkeys (Macaca mulatto): Evidence for Functionally Independent Oxytocinergic Pathways in Primates. Journal of Clinical Endocrinology and Metabolism 71(6): 1531-1535.

Bartz J.A., Zaki J., Bolger N., and Ochsner K.N. 2011. Social effects of oxytocin in humans: context and person matter. Trends in Cognitive Science 15(7): 301-309.

Born J., Lange T., Kern W., McGregor G.P., Bickel U., and Fehm H.L. 2002. Sniffing neuropeptides: a transnasal approach to the human brain. Nature Neuroscience 5(6): 514-516.

Brennan K.A., Clark C.L., and Shaver P.R. 1998. Selfreport measurement of attachment: An intergrative overview. In Attachment theory and close relationships, 4676, ed. J. A. Simpson and W. S. Rholes. New York: Guilford Press.

Bretherton I. and Munholland K.A. 2008. Internal working models in attachment relationships: Elaborating a central construct in attachment theory. In Handbook of attachment: Theory, research, and clinical applications (2nd ed.), 102-130, ed. J. Cassidy and P. R. Shaver. New York: Guilford Press.

Chen F.S., Barth M.E., Johnson S.L., Gotlib I.H., and 
Johnson, S.C. 2011. Oxytocin receptor (OXTR) polymorphisms and attachment in human infants. Frontiers in Psychology 2. doi: 10.3389/fpsyg.2011.00200

Christensen, J. C., Shiyanov, P. A., Estepp, J. R., and Schlager, J. L. 2014. Lack of association between human plasma oxytocin and interpersonal trust in a prisoner's dilemma paradigm. PLoS ONE 9(12): e116172. doi:10.1371/journal.pone.0116172

Dal Monte O., Noble P.L., Costa V.D., and Averbeck B.B. 2014. Oxytocin enhances attention to the eye region in rhesus monkeys. Frontiers in Neuroscience 8. doi: 10.3389/fnins.2014.00041

Dal Monte O., Noble P.L., Turchi J., Cummins A., and Averbeck B.B. 2014. CSF and blood oxytocin concentration changes following intranasal delivery in Macaque. PLoS ONE 9(8): e103677. doi: 10.1371/journal.pone.0103677

Denes A. 2015. Genetic and individual influences on predictors of disclosure: exploring variation in the oxytocin receptor gene and attachment security. Communication Monographs 82(1): 113-133.

de Oliveira D.C.G., Zuardi A.W., Graeff F.G., Queiroz R.H.C., and Crippa J.A.S. 2012. Anxiolytic-like effect of oxytocin in the simulated public speaking test. Journal of Psychopharmacology 26(4): 497-504.

Dickstein S., Thompson R.A., Estes D., Malkin C., and Lamb M.E. 1984. Social referencing and the security of attachment. Infant Behavior and Development 7: 507-516.

Dwyer F., Bennett P.C., and Coleman G.J. 2006. Development of the Monash dog owner relationship scale (MDORS). Anthrozoös 19(3): 243-256.

Engelmann M., Wotjak C.T., Ebner K., and Landgraf R. 2000. Behavioural impact of intraseptally released vasopressin and oxytocin in rats. Experimental Physiology 85S: 125S-130S.

Gabor C.S., Phan A., Clipperton-Allen A.E., Kavaliers M., and Choleris E. 2012. Interplay of oxytocin, vasopressin, and sex hormones in the regulation of social recognition. Behavioral Neuroscience 126(1): 97-109.

Guastella A.J., Mitchell P.B., and Dadds M.R. 2008. Oxytocin increases gaze to the eye region of human faces. Biological Psychiatry 63(1): 3-5.

Handlin L., Hydbring-Sandberg E., Nilsson A., Ejdebäck M., Jansson A., and Uvnäs-Moberg K. 2011. Short-term interaction between dogs and their owners: effects of oxytocin, cortisol, insulin and heart-rate - an exploratory study. Anthrozoös 24(3): 301-315.

Heinrichs M., Baumgartner T., Kirschbaum C., and Ehlert U. 2003. Social support and oxytocin interact to suppress cortisol and subjective responses to psychosocial stress. Biological Psychiatry 54(12): 13891398. doi: 10.1016/S0006-3223(03)00465-7

Hennessy M.B., Davis H.N., Williams M.T., Mellott C., and Douglas C.W. 1997. Plasma cortisol levels of dogs at a county animal shelter. Physiology and Behavior 62(3): 485-490.

Hennessy M.B., Williams M.T., Miller D.D., Douglas C.W., and Voith V.L. 1998. Influence of male and female petters on plasma cortisol and behaviour: can human interaction reduce the stress of dogs in a public animal shelter? Applied Animal Behaviour Science 61: 63-77.

Howell T.J., Toukhsati S., Conduit R., and Bennett P. 2013. The perceptions of dog intelligence and cognitive skills (PoDIaCS) survey. Journal of Veterinary Behavior 8(6): 418-424.

Hernádi A., Kis A., Kanizsár O., Tóth K., Miklósi B., and Topál J. 2015. Intranasally administered oxytocin affects how dogs (Canis familiaris) react to the threatening approach of their owner and an unfamiliar experimenter. Behavioural Processes 119: 1-5. doi: 10.1016/j.beproc.2015.07.001

IMB Corp. (2013) IBM SPSS Statistics for Windows, Version 22.0. IBM Corp., Armonk.

Kis A., Bence M., Lakatos G., Pergel E., Turcsán B., 
Pluijmakers J., Vas J., Elek Z., Brúder I., Földi L., Sasvári-Székely M., Miklósi A., Rónai Z., and Kubinyi E. 2014. Oxytocin receptor gene polymorphisms are associated with human directed social behavior in dogs (Canis familiaris). PloS one 9(1): e83993. doi: 10.1371/journal.pone.0083993

Kis A., Hernádi A., Kanizsár O., Gácsi M., and Topál J. 2015. Oxytocin induces positive expectations about ambivalent stimuli (cognitive bias) in dogs. Hormones and Behavior 69: 1-7. doi: 10.1016/j.yhbeh.2014.12.004

Leng, G., Ludwig, M. 2016. Intranasal Oxytocin: Myths and Delusions. Biological Psychiatry 79(3): 243-250.

Lucht M.J., Barnow S., Sonnenfeld C., Rosenberger A., Grabe H.J., Schroeder W., Volzke H., Freyberger H.J., Herrmann F.H., Kroemer H., and Rosskopf D. 2009. Associations between the oxytocin receptor gene (OXTR) and affect, loneliness and intelligence in normal subjects. Progress in Neuro-psychopharmacology 33(5): 860-866.

Ludwig M., and Leng G. 2006. Dendritic peptide release and peptide-dependent behaviours. Nature Reviews Neuroscience 7(2): 126-136. doi: 10.1038/nrn1845

McCullough, M. E., Churchland, P. S., and Mendez, A. J. 2013. Problems with measuring peripheral oxytocin: Can the data on oxytocin andhuman behavior be trusted? Neuroscience and Biobehavioral Reviews 37: 14851492.

Miller S.C., Kennedy C., DeVole D., Hickey M., Nelson T., and Kogan L. 2009. An examination of changes in oxytocin levels in men and women before and after interaction with a bonded dog. Anthrozoös 22(1): 31-42.

Mitsui S., Yamamoto M., Nagasawa M., Mogi K., Kikusui T., Ohtani N., and Ohta M. 2011. Urinary oxytocin as a noninvasive biomarker of positive emotion in dogs. Hormones and Behavior 60(3): 239-243.

Nagasawa M., Kikusui T., Onaka T., and Ohta M. 2009. Dog's gaze at its owner increases owner's urinary oxytocin during social interaction. Hormones and
Behavior 55(3): 434-441.

Nagasawa M., Mitsui S., En S., Ohtani N., Ohta M., Sakuma Y., Onaka T., Mogi K., and Kikusui T. 2015. Oxytocin-gaze positive loop and the coevolution of human-dog bonds. Science 348(6232): 333-336. doi: 10.1126/science.1261022

Neumann, I. D., Maloumby, R., Beiderbeck, D. I., Lukas, M., and Landgraf, R. 2013. Increased brain and plasma oxytocin after nasal and peripheral administration in rats and mice. Psychoneuroendocrinology 38: 1985-1993.

Oliva J.L., Rault J-L., Appleton B., and Lill A. 2015. Oxytocin enhances the appropriate use of human social cues by the domestic dog (Canis familiaris) in an object choice task. Animal Cognition 18: 767-775. doi: 10.1007/s10071-015-0843-7

O'Farrell V. 1997. Owner attitudes and dog behaviour problems. Applied Animal Behaviour Science 52(3-4): 205213.

Odendaal J.S. 2000. Animal-assisted therapy - magic or medicine? Journal of Psychosomatic Research 49(4): 275280.

Odendaal J.S., and Meintjes R.A. 2003. Neurophysiological correlates of affiliative behaviour between humans and dogs. Veterinary Journal 165(3): 296-301.

Pang J-F., Kluetsch C., Zou X-J., Zhang A-b., Luo L-Y., Angleby H., Ardalan A., Ekström C., Sköllermo A., Lundeberg J., Matsumura S., Leitner T., Zhang Y-P., and Savolainen P. 2009. mtDNA data indicate a single origin for dogs south of Yangtze River, less than 16,300 years ago, from numberous wolves. Molecular Biology and Evolution 26(12): 2849-2864.

Rault J-L. 2016. Effects of positive and negative human contacts and intranasaloxytocin on cerebrospinal fluid oxytocin. Psychoneuroendocrinology, 69: 60-66.

Robinson I.C. 1983. Neurohypophysial peptides in 
cerebrospinal fluid. Progress in Brain Research 60: 129145.

Robinson I.C., Jones P.M. 1982. Oxytocin and neurophysin in plasma and CSF during suckling in the guinea-pig. Neuroendocrinology 34(1): 59-63.

Rodrigues S.M., Saslow L.R., Garcia N., John O.P., and Keltner D. 2009. Oxytocin receptor genetic variation relates to empathy and stress reactivity in humans. Proceedings of the National Academy of Sciences USA 106(50): 21437-21441.

Striano T., Vaish A., and Benigno J.P. 2006. The meaning of infants' looks: information seeking and comfort seeking? British Journal of Developmental Psychology 24: 615-630.

Striepens N., Kendrick K. M., Hanking V., Landgraf R., Wullner U., Maier W., and Hurlemann R. 2013. Elevated cerebrospinal fluid and blood concentrations of oxytocin following its intranasal administration in humans. Scientific Reports 3: 3440. doi: 10.1038/srep03440

Szeto A., McCabe P.M., Nation D.A., Tabak M.S., Rossetti M.A., McCullough M.E., Schneiderman N., and Mendez A.J. 2011. Evaluation of enzyme immunoassay and radioimmunoassay methods for the measurement of plasma oxytocin. Psychosomatic Medicine 73(5): 393-400. doi: 10.1097/PSY.0b013e31821df0c2
Topál J., Gácsi M., Miklósi Á., Virányi Z., Kubinyi E., and Csányi V. 2005. Attachment to humans: a comparative study on hand-reared wolves and differently socialized dog puppies. Animal Behavior 70: 1367-1375.

Tost H., Kolachana B., Hakimi S., Lemaitre H., Verchinski B.A., Mattay V.S., Weinberger D.R., and Meyer-Lindenberg A. 2010. A common allele in the oxytocin receptor gene (OXTR) impacts prosocial temperament and human hypothalamic-limbic structure and function. Proceedings of the National Academy of Sciences USA 107(31): 13936-13941.

Veening J.G., de Jong T., and Barendregt H.P. 2010. Oxytocin-messages via the cerebrospinal fluid: behavioral effects; a review. Physiology and Behavior 101(2): 193-210.

Volkmar F.R. 2011. Understanding the social brain in autism. Developmental Psychobiology 53(5): 428-434.

Wu S., Jia M., Ruan Y., Liu J., Guo Y., Shuang M., Gong X., Zhang Y., Yang X., and Zhang D. 2005. Positive association of the oxytocin receptor gene (OXTR) with autism in the Chinese Han population. Biological Psychiatry 58(1): 74-77.

Zilcha-Mano S., Mikulincer M., and Shaver P.R. 2011. An attachment perspective on human-pet relationships: conceptualization and assessment of pet attachment orientations. Journal of Research in Personality 45: 345357. 